RESEARCH REPORT

\title{
Employment, working conditions, and preterm birth: results from the Europop case-control survey
}

\section{J Saurel-Cubizolles, J Zeitlin, N Lelong, E Papiernik, G C Di Renzo, G Bréart, for the Europop group*}

J Epidemiol Community Health 2004;58:395-401. doi: 10.1136/jech.2003.008029
See end of article for authors' affiliations

.....................

Correspondence to: Dr M J Saurel-Cubizolles, Inserm Unité 149, 16 avenue Paul VaillantCouturier, 94807 Villejuif cedex, France; saurel@ vif.inserm.fr

Accepted for publication 18 July 2003

\begin{abstract}
Study objective: To analyse the relation between preterm birth and working conditions in Europe using common measures of exposure and to test whether employment related risks varied by country of residence.

Design: A case-control study in which cases included all consecutive singleton preterm births and controls included one of every ten singleton term births in each participating maternity unit. Data about working conditions were obtained by interview from women after delivery.

Setting: Sixteen European countries.

Participants: The analysis included 5145 preterm and 7911 term births of which 2369 preterm and 4098 term births were to women employed during pregnancy. Analyses of working conditions were carried out for women working through at least the third month of pregnancy.

Main results: Employed women did not have an excess risk of preterm birth. Among working women, a moderate excess risk was observed for women working more than 42 hours a week $(O R=1.33, \mathrm{Cl}=1.1$ to 1.6), standing more than six hours a day $(\mathrm{OR}=1.26, \mathrm{Cl}=1.1$ to 1.5$)$, and for women with low job satisfaction (OR $=1.27, \mathrm{Cl}=1.1$ to 1.5 ). There were stronger links in countries with a lower overall level of perinatal health and a common practice of long prenatal leaves.

Conclusion: These findings show that specific working conditions affect the risk of preterm birth. They also suggest employment related risks could be mediated by the social and legislative context.
\end{abstract}

$\mathrm{S}$ tudies on the relation between employment and preterm delivery have yielded contradictory results. ${ }^{1}$ The decision to work during pregnancy reflects a large variety of factors such as education, social support, and health status that are independently linked to the risks of preterm birth. ${ }^{2-4}$ In many studies, women who are employed have a lower risk of preterm birth than women who are not employed. ${ }^{125}$

None the less, a broad range of studies have found that certain working conditions, in particular physically strenuous or fatiguing work, increase the risk of preterm birth. ${ }^{6}$ Identifying employment related risk factors for preterm delivery is of particular importance because these risks are amenable to change through policies granting work leaves or modifying working conditions during pregnancy. In contrast, most other risk factors for preterm birth cannot easily be changed.

Studies of working conditions and pregnancy outcomes have not always identified the same working conditions as high risk and some studies have found no relation with preterm birth..$^{7-9}$ The variability in study results could be attributable to the use of different measures of working conditions, different methods of collecting data on exposure (prospectively or retrospectively), or the choice of sociodemographic control variables. Adjusting for sociodemographic characteristics affects measures of risk levels considerably, as occupational category is highly related to social characteristics. ${ }^{4}$

Another possible source of variation between studies is the legislative and social context. If women with high risk pregnancies are granted leaves early in pregnancy then levels of exposure in the population of pregnant women will be lower. This could have the effect of attenuating observable effects. In French studies on work and preterm birth, for instance, the magnitude of the risk associated with certain working conditions is lower in studies done in the 1980s than those from the 1970s, which could be related to the increasing of leaves during pregnancy. ${ }^{10}$ Social context may also influence employment related risks in broader ways, by determining the characteristics of the population of women who do work (related to unemployment benefits or economic pressures), by affecting social support outside of the work place or because of an interaction of these risks with the general standards of living of the working population. These hypotheses are difficult to address in most studies. For instance, because women with high risk pregnancies are both more likely to stop work and more likely to deliver before term, testing the impact of pregnancy leave policies on preterm birth on an individual level is difficult. ${ }^{11}$ Similarly, variability in community characteristics is necessary for measuring the impact of social context on risk. Comparing risk levels between groups of countries is one approach that can be used to explore these questions. ${ }^{12}$

The Europop study aimed to derive common measures of the impact of employment conditions on preterm birth in Europe using comparable measures of these conditions. The European context is of interest because most countries have implemented social policies granting women paid leaves in pregnancy and limiting exposure to onerous working conditions during pregnancy. ${ }^{13}$ The Europop study included 17 European countries, making it possible to analyse further the variation in risk in subgroups of countries defined in relation to levels of infant mortality and practices related to leave in pregnancy.

*Members of the Europop group are show in the appendix. 
Table 1 Working conditions and preterm birth: distributions and adjusted odds ratios

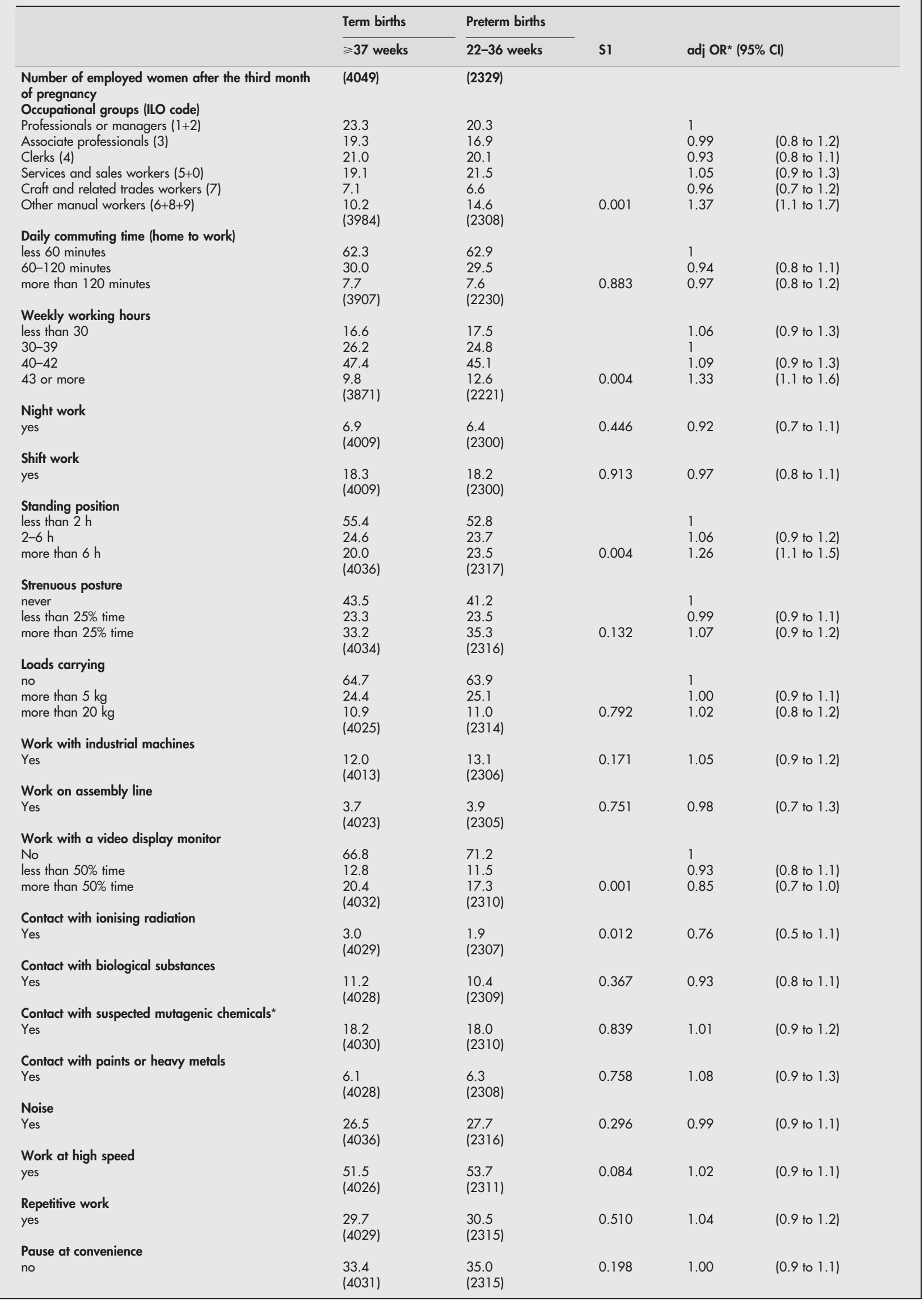


Table 1 Continued

\begin{tabular}{|c|c|c|c|c|c|}
\hline & Term births & Preterm births & & & \\
\hline & $\geqslant 37$ weeks & $22-36$ weeks & S1 & adj $O$ & \\
\hline no & $\begin{array}{l}34.3 \\
(4031)\end{array}$ & $\begin{array}{l}36.9 \\
(2314)\end{array}$ & 0.034 & 1.11 & (1.0 to 1.2 ) \\
\hline $\begin{array}{l}\text { Job satisfaction } \\
\text { very satisfied } \\
\text { satisfied } \\
\text { not satisfied }\end{array}$ & $\begin{array}{l}37.6 \\
50.1 \\
12.3 \\
(4034)\end{array}$ & $\begin{array}{l}37.8 \\
47.1 \\
15.1 \\
(2317)\end{array}$ & 0.004 & $\begin{array}{l}1 \\
0.99 \\
1.27\end{array}$ & $\begin{array}{l}(0.9 \text { to } 1.1) \\
\text { (1.1 to } 1.5)\end{array}$ \\
\hline
\end{tabular}

$\mathrm{S} 1$ is the $\mathrm{p}$ value comparing both distributions, $\chi^{2}$ test. *Adjusted for age, educational level, marital status, obstetrical history, and country. One model was calculated for each of the variables describing working conditions.

\section{METHODS}

\section{The survey}

The Europop study is an unmatched case-control study that was conducted between 1994 and 1997 using the same protocol in participating maternity units in 17 European countries: Finland, France, Germany, Greece, Hungary, Ireland, Italy, Poland, Slovenia, Scotland, Spain, Sweden, the Czech Republic, the Netherlands, Romania, Russia, and Turkey. Cases were all consecutive singleton preterm deliveries (22-36 completed weeks of gestation) over the study period. The control group included every tenth consecutive full term singleton birth (37 weeks of gestation or over) over the same period. Data collection took place over one year or until 200 cases had been included. Classification was based on obstetric estimation of gestational age using ultrasound examination and the timing of the last menstrual period.

Data from Turkey were excluded because the control group was incomplete. Stillbirths were included in the survey, except in Scotland where data were collected only for live births.

Data were collected in all countries using the same questionnaire, previously published elsewhere. ${ }^{14}$ Information on social and demographic characteristics, occupation, working conditions, and obstetric history was obtained by interview with the woman at the maternity ward after the delivery, while information on the pregnancy, delivery, the vital status of the newborn or the fetus, and gestational age at delivery was extracted directly from medical records.

\section{Indicators included in the analysis}

The dependent variable was preterm birth. Employment status and working conditions were the explanatory factors under investigation. Women who worked at any time during pregnancy (defined as work other than housework) irrespective of duration and timing were defined as employed. All other women were classified as non-employed.

Working conditions were ascertained for the first three months of the pregnancy. Occupation was coded using the International Standard Classification of Occupations, ISCO$88 .{ }^{15}$ The variables describing working conditions, presented by category in table 1 , included the daily time commuting from home to work, weekly working hours, night work, shift work, standing position, strenuous postures (bending, twisting, kneeling, squatting or holding arms at shoulder level or above), carrying heavy loads, work with industrial machines, assembly line work, work with a video display monitor, some specific exposures such as ionising radiation, biological substances (blood, animal bodies, infectious materials), suspected mutagenic chemicals (anaesthetic gases, solvents, disinfectant substances, antineoplastic drugs), paints or heavy metals (paints, dyes, mercury, lead, cadmium), noise (measured by the following question: "At work were you exposed to noise so loud that you had to raise your voice to talk to people?"; women who answered occasionally, often, or very often were considered as exposed), some indicators of mental loads such as work at high speed, repetitive work, lack of pause (no rest room or other pauses at own convenience), lack of autonomy (no choice concerning the order of the tasks, the method of work or the speed or rate of work), and a global indicator of satisfaction with the job.

The analysis included the following confounding factors: maternal age (coded as under 20, 20-24, 25-29, 30-34, and 35 or over); women's educational level defined as age at the end of schooling (under 16,16 or 17,18 or 19 , and 20 or over); marital status (women living without partner, cohabiting unmarried women, and married women); and obstetric history (primigravidae, multigravidae without previous abortion nor preterm birth, multigravidae with previous first trimester abortion, multigravidae with previous preterm delivery or second trimestrer abortion). The country of residence was included as a dummy variable in all multivariate models.

\section{Definition of sample for analyses}

The study included 5456 cases and 8254 controls. Subjects with missing data on employment status were excluded, leaving a final sample of 5145 preterm births and 7911 term births of which 2801 and 4614 respectively were to mothers employed at any time during pregnancy. For the analysis of working conditions, however, we included only women who worked for at least three months from the start of pregnancy, based on the assumption that there is a minimum duration of exposure before a working condition becomes a risk factor for preterm birth. The final sample for the analysis of the relation between working conditions and preterm birth thus included 2369 preterm births and 4098 term births to women who were still working after the third month of pregnancy. Sample sizes varied slightly from one variable to another because of missing data on specific working conditions, as shown in table 1 .

\section{Statistical analyses}

The preterm births group was compared with controls for all working situations by simple bivariate analyses, using a $\chi^{2}$ test. To control for confounding factors, logistic regression models were run separately for each measure of work conditions adjusting for confounders.

We also explored the relation between preterm birth and working conditions within subgroups of countries. We stratified our data according two criteria. The first criterion we used was the infant mortality rate. This indicator, external to the survey, is an indicator of health status, especially in the perinatal period, as well as of economic and social conditions. We separated the four countries-Hungary, Poland, Romania, and Russia-that had an infant mortality rate higher than 10.0 infant deaths per 1000 live births ${ }^{16}$ in 1995 


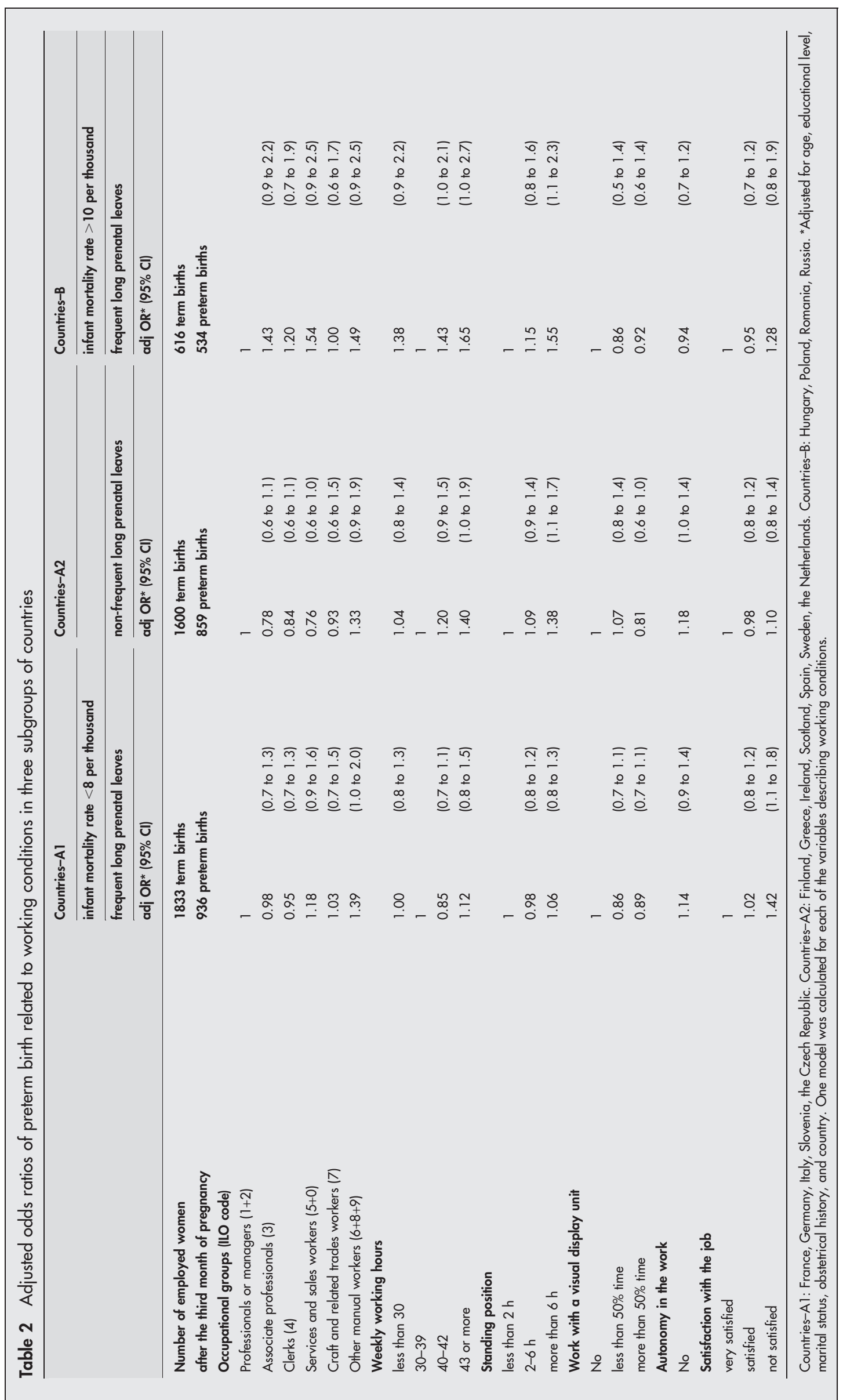


(labelled B countries) from the other 12 countries (labelled A countries). For the A countries, the infant mortality rate varied from 3.9 (in Finland) to 7.9 (in Greece) per 1000 live births.

The second criterion was an indicator of social context related to our subject: practices concerning work leave during pregnancy. Individual level variables could not be used to measure the impact of work leave policies on risks because of the selection bias associated with stopping work. This "healthy pregnancy" effect was evident in this sample: 35\% of controls stopped work before the third trimester compared with $52 \%$ of cases. A variable was defined at the country level as the percentage of women in the Europop control group who had stopped working before the end of the second trimester of pregnancy. Comparable data on work leave practices during pregnancy were not available from external sources. In the Europop sample, there was a considerable difference in practices concerning work leave among controls in the A countries allowing us to constitute two distinct groups. In group one, those with frequent long prenatal leaves, between one third and two thirds of working women had stopped before the third trimester (average for the group $44 \%$ ). In group A2, where long prenatal leaves were less frequent, between $11 \%$ and $22 \%$ of women had stopped before the third trimester (average for the group 16\%). Group Al included France, Germany, Italy, Slovenia, and the Czech Republic_and group A2 Finland, Greece, Ireland, Scotland, Spain, Sweden, and the Netherlands. There was not sufficient variability to carry out this analysis in the four B countries where about half of women had not worked during the third trimester. In each subgroup, we performed logistic regression models for each work factor with a p value lower than 0.10 in the first set of analyses.

All $\mathrm{p}$ values were for two tailed tests. The analysis was performed using SAS statistical software.

\section{RESULTS}

Fifty four per cent of women who had a preterm birth were employed during pregnancy compared with $58.3 \%$ in the control group $(\mathrm{OR}=0.85,95 \%$ confidence intervals: 0.80 to $0.92, \mathrm{p}<0.001)$. After adjustment for confounding factors, the difference was no longer significant, with an odds ratio for employment during pregnancy of 0.93 (95\% CI: 0.86 to 1.01 ).

Table 1 describes the relation between working conditions and preterm birth among women working for more than three months from the start of pregnancy. After adjustment, other manual workers, a category that includes industrial, agricultural, and unskilled workers had an excess of preterm births compared with professionals and associates. Women working long hours (more than 42 hours, compared with 3039 hours), those working in a standing position for more than six hours a day, and women reporting dissatisfaction towards their job also had a significantly higher risk. No other working conditions were related to an excess risk of preterm birth. Work with a video display monitor was highly significant and protective for preterm birth in univariate analysis, but is no longer significant after adjustment. For working situations negatively related to preterm birth, the magnitude of the associations was moderate with adjusted odds ratios about 1.3 or less.

The relation between preterm birth and occupational conditions was not the same in all subgroups of countries as shown in table 2. Other manual workers had increased odds ratios in all countries, although in countries A2 and B the confidence interval included 1 . In the B countries, service and sales workers also had increased odds of preterm delivery. Relative risks related to long working hours and long standing position were highest in B countries, with odds ratios over 1.5. In the $\mathrm{B}$ countries, an excess risk was observed for women having to work 40 to 42 hours a week as well as women working over 42 hours. In contrast, no excess risk was observed related to these working conditions in $\mathrm{Al}$ countries. In the A2 countries, the situation was intermediate with odds ratios higher than unity. The relation between preterm birth and work with visual display unit was insignificant in all three groups of countries. Women who reported no autonomy at work had a slight excess risk of preterm birth in the A countries, that was not observed in the B countries. Dissatisfaction towards the job was significantly related to the outcome in the $\mathrm{Al}$ countries, no difference was observed in the A2 countries and a slight excess, although insignificant, was reported in the B countries.

\section{DISCUSSION}

These results, obtained from a large European case-control study in the mid-90s, show a moderate excess risk of preterm birth for pregnant women employed as manual workers and for those working long hours, standing for long periods, and reporting dissatisfaction with their job. For long standing position and long working hours, the magnitude of the association was larger in the four countries of Eastern Europe, where the perinatal health status, measured by infant mortality, is not as good. In countries with lower infant mortality rates, no significant association was observed in the group of countries where women had longer prenatal leaves whereas significant associations were observed in countries where women worked longer in the pregnancy.

This study had a multicentre case-control design. Its strengths are the large numbers of preterm births, the diversity of participating centres and the use of a common protocol, including an identical instrument for collecting information on the characteristics of the sample and working conditions. The same questions were asked of all women concerning their employment conditions. The limitation of this study, however, is its case-control design: an information bias could exist if the mothers of preterm infants did not answer the questionnaire in the same way as controls.

In analyses, we were able to control for key confounding factors: maternal age, educational level, marital status, and obstetric history. These four factors are strongly related to preterm birth in this sample. ${ }^{17}$ While employment during pregnancy was more frequent among controls than among cases, this was explained by differences in sociodemographic factors between the two groups. After adjustment, employment was not in itself a significant predictor of the risk of preterm birth. Controlling for sociodemographic factors is important for adjusting for differences in social status that could be associated with individual working conditions and preterm birth. For instance, the protective effect of work with video display monitors in univariate analyses seemed to be linked to the socioeconomic and demographic characteristics of the women working in jobs using computers; this effect was insignificant once adjustments were made for education and age.

Women considered as exposed for these analyses worked for at least the first three months of pregnancy. While the critical period of exposure may differ for specific working conditions, many of the working conditions studied in this analysis were related to physical exertion, postural constraints, fatigue, or psychological influences, for which duration of exposure would be important. The magnitude of the observed associations between working conditions and preterm birth was moderate: odds ratios were about 1.3 for individual working conditions and the thresholds at which an impact was observed was comparatively high. None the less, between $10 \%$ and $20 \%$ of women in the control 
population were exposed to these conditions during pregnancy.

The two individual working conditions that were associated with preterm birth, standing and long working hours, have been identified as risk factors in many other studies. ${ }^{8}{ }^{18-24}$ A recent meta-analysis of 29 studies on working conditions reported an OR of 1.25 for prolonged standing (defined as greater than three hours per day). ${ }^{6}$ While individual studies have reported associations with long working hours, ${ }^{19-21} 24$ the meta-analysis found no excess risk associated with long working hours. However, their definition of a long week was a working week over 39 hours. In our analyses, the excess risk associated with working hours was only observed for working weeks over 42 hours.

Some of the associations identified in the meta-analysis were not found in this sample, such as a higher risk for shift and night work. In the meta-analysis, common measures were: OR of 1.22 for physically demanding work, 1.24 for shift and night work, and 1.63 for cumulative fatigue. ${ }^{6}$ Manual workers had a higher risk of preterm birth in our sample, but individual measures of physically demanding work (carrying loads, work at high speeds) were not associated with preterm birth.

Our results suggest that women dissatisfied with their jobs have an excess of preterm births. Measures of satisfaction are not usually included in studies on work and preterm birth, so it is difficult to compare this result with others. The results of studies on psychological stress at work and preterm birth are inconclusive, although most of them have not reported a significant $\operatorname{link}^{25-27}$ as in this study, where no association is observed between preterm birth and repetitive work, work at high speed, or lack of autonomy. It is possible that job dissatisfaction is a global proxy for various negative situations. It is not clear why this relation is more pronounced in the Al countries than in the other groups of countries.

The results of the analysis by groups of countries are consistent with our hypothesis that the social and legislative context has a role in determining the effects of individual level exposures on preterm delivery, although differences between groups were not statistically significant. The magnitude of the effect of working conditions was greatest in the countries of Eastern Europe (B countries). Service and sales workers also had a higher risk in these countries in addition to manual workers who were at greater risk in all three groups of countries. Service and sales workers have been found to be a group at higher risk of adverse perinatal outcomes in other research..$^{28}$ In addition, in the five countries with a low infant mortality rate and long prenatal leaves, standing and long working hours were not significantly related to the risk of preterm birth. This was not the case in the other group of countries, where long prenatal leaves were less frequent.

One hypothesis was that implementing policies to limit work related health risks would attenuate the impact of these risks. This interpretation has been put forth to explain the absence of an effect in Swedish studies of working conditions and pregnancy outcomes ${ }^{70}$ as well as the changing impact of working conditions on preterm birth in France. ${ }^{10}$ This hypothesis would not be sufficient to explain differences between A and B countries, as a significant proportion of pregnant women in the $\mathrm{B}$ countries stopped work in the second trimester of pregnancy. However, it is possible that the reasons for stopping work were not the same in these countries and that work leaves do not target populations at risk of preterm birth. ${ }^{31}$ Alternatively, other community level factors, such as support at home or social and healthcare policies, could play a mediating part in determining exposure to employment related risks.
In conclusion, this study corroborates results from other studies in relation to specific employment conditions and the risk of preterm birth. It also suggests that conflicting findings from studies on this topic could be related to the social and legislative environment. Work leave policies and the impact of these policies on the population of women exposed to high risk employment conditions should be considered in future analyses.

\section{ACKNOWLEDGEMENTS}

We would like to thank the many people in each participating country who collected the data.

\section{Authors' affiliations}

M J Saurel-Cubizolles, J Zeitlin, N Lelong, G Bréart, Inserm, Unité 149IFR69, Villejuif, France

E Papiernik, University René Descartes, Service de Gynécologie-

Obstétrique de Port-Royal, Paris, France

G C Di Renzo, Department of Gynaecology, Obstetric and Paediatric Sciences University of Perugia, Italy

Funding: this study was funded by the European Union, contract number BMH1-CT94-1041.

Conflicts of interest: none declared.

\section{APPENDIX}

The following people were members of the EUROPOP group:

\section{Steering committee}

Project leader: Di Renzo GC, Perugia, Italy; Bréart G, Paris, France; Papiernik E, Paris, France; Patel N, Dundee, United Kingdom; Saurel-Cubizolles MJ, Villejuif, France; Taylor D, Leicester, United Kingdom; Todini S, Perugia, Italy.

\section{Members of the National Staffs}

Czech Republic: Kudela M, MD, Vetr M, MD, in Olomouc; Finland: Heikkilä A, MD, Erkkola R, MD, Forström J , MD, in Turku; France: Papiernik E, MD, Lucidarme P, midwife, in Paris. Tafforeau J, MD, in Brussels; Germany: Künzel W, MD, Herrero-Garcia J, MD, in Giessen. Dudenhausen J, MD, Henrich W, MD, in Berlin; Greece: Antsaklis A, MD, Haritatos G , MD, in Athens; Hungary: Kovacs L, MD, Nyari T, MD, Bartfai G, MD, in Szeged; Ireland: O'Herlihy C, MD, Murphy $\mathrm{J}, \mathrm{MD}$, Stewart $\mathrm{H}$, in Dublin; Italy: Di Renzo GC, MD, Bruschettini PL, MD, Moscioni P, MD, in Perugia. Cosmi E, $\mathrm{MD}$, Spinelli A, MD, Serena D, MD, in Rome; Poland: Breborowicz GH, MD, Anholcer A, MD, in Poznan; Romania: Stamatian F, MD, in Cluj; Russia: Mikhailov AV, MD, in St Petersburg; Slovenia: Pajntar M, MD, Pirc M, MD, Verdenik I, $\mathrm{MD}$, in Ljubljana; Spain: Escribà-Aguir V, MD, in Valencia. Carrera JM , MD, in Barcelona; Sweden: Marsal K, MD, Stale H, MD, in Malmö; the Netherlands: Buitendijk S, Ph.D, van der Pal K, MsC, in Leiden. van Geijn H, MD, in Amsterdam; Turkey: Gökmen O, MD, Güler C, MD, Caglar T, MD, in Ankara; United Kingdom: Owen P, MD, in Dundee.

\section{REFERENCES}

1 Saurel-Cubizolles MJ, Kaminski M. Work in pregnancy: its evolving relationship with perinatal outcome. Soc Sci Med 1986;22:431-42.

2 Marbury MC, Linn S, Monson RR, et al. Work and pregnancy. J Occup Med 1984;26:415-21.

3 Henriksen TB, Savitz DA, Hedegaard M, et al. Employment during pregnancy in relation to risk factors and pregnancy outcome. Br J Obstet Gynaecol 1994;101:858-65.

4 Savitz DA, Whelan EA, Rowland AS, et al. Maternal employment and reproductive risk factors. Am J Epidemiol 1990;132:933-45.

5 Murphy JF, Dauncey M, Newcombe R, et al. Employment in pregnancy: prevalence, maternal characteristics, perinatal outcome. Lancet 1984;i:1163-6.

6 Mozurkewich EL, Luke B, Avni M, et al. Working conditions and adverse pregnancy outcome: a meta-analysis. Obstet Gynecol 2000;95:623-35.

7 Ahlborg G Jr, Bodin L, Hogstedt C. Heavy lifting during pregnancy-a hazard to the fetus? A prospective Study. Int J Epidemiol 1990;19:90-7. 
8 Klebanoff MA, Shiono P, Carey JC. The effect of physical activity during pregnancy on preterm delivery and birth weight. Am J Obstet Gynecol 1990;163:1450-6.

9 Fortier I, Marcoux S, Brisson J. Maternal work during pregnancy and the risks of delivering a small-for- gestational-age or preterm infant. Scand J Work Environ Health 1995;21:412-18.

10 Saurel-Cubizolles MJ, Subtil D, Kaminski M. Is preterm delivery still related to physical working conditions in pregnancy? J Epidemiol Community Health 1991;45:29-34.

11 Frazier LM, Golbeck AL, Lipscomb L. Medically recommended cessation of employment among pregnant women in Georgia. Obstet Gynecol 2001:97:971-5.

12 Zeitlin JA, Saurel-Cubizolles MJ, Ancel PY. Marital status, cohabitation, and risk of preterm birth in Europe: where births outside marriage are common and uncommon. Paediatr Perinat Epidemiol 2002;16:124-30.

13 Di Renzo G, Moscioni P, Perazzi A, et al. Social policies in relation to employment and pregnancy in European countries. Prenat Neonat Med 1998;3: 147-56.

14 Saurel-Cubizolles MJ, Di Renzo G, Bréart G. The Europop Group. Women's work and preterm birth: epidemiological knowledge and description of a European project. Prenat Neonat Med 1997;2:161-80.

15 International Labour Office. International Standard Classification of Occupations: ISCO-88. Geneva: International Labour Office, 1991.

16 Boucher M. Tous les pays du monde. Population and Sociétés 1997;326:1-8.

17 Ancel PY, Saurel-Cubizolles MJ, Di Renzo GC, et al. Very and moderate preterm births: are the risk factors different? $\mathrm{Br} J$ Obstet Gynaecol 1999; 106:1162-70.

18 Henriksen TB, Hedegaard M, Secher NJ, et al. Standing at work and preterm delivery. Br J Obstet Gynaecol 1995;102:198-206.

19 Luke B, Mamelle N, Keith L, et al. The association between occupational factors and preterm birth: a United States nurses' study. Research Committee of the Association of Women's Health, Obstetric, and Neonatal Nurses. Am J Obstet Gynecol 1995; 173:849-62.

20 Mamelle N, Laumon B, Lazar P. Prematurity and occupational activity during pregnancy. Am J Epidemiol 1984;119:309-22.

21 McDonald AD, McDonald JC, Armstrong $B$, et al. Prematurity and work in pregnancy. $\mathrm{Br} J$ Ind Med 1988;45:56-62.

22 Launer $\mathrm{L}$, Villar J, Kestler $\mathrm{E}$, et al. The effect of maternal work on fetal growth and duration of pregnancy: a prospective study. Br J Obstet Gynaecol 1990:97:62-70.

23 Saurel-Cubizolles MJ, Kaminski M, Llado-Arkhipoff J, et al. Pregnancy and its outcome among hospital personnel according to occupation and working conditions. J Epidemiol Community Health 1985;39:129-34.

24 Saurel-Cubizolles MJ, Kaminski M, Rumeau-Rouquette C. [Occupational activities of pregnant women, prenatal care and pregnancy outcome]. $J$ Gynecol Obstet Biol Reprod 1982;11:959-67.

25 Henriksen TB, Hedegaard M, Secher NJ. The relation between psychosocial job strain, and preterm delivery and low birthweight for gestational age. Int J Epidemiol 1994;23:764-74.

26 Homer CJ, James SA, Siegel E. Work-related psychosocial stress and risk of preterm, low birthweight delivery. Am J Public Health 1990;80:173-7.

27 Brett KM, Strogatz DS, Savitz DA. Employment, job strain, and preterm delivery among women in North Carolina. Am J Public Health 1997;87:199-204.

28 Savitz DA, Olshan AF, Gallagher K. Maternal occupation and pregnancy outcome. Epidemiology 1996;7:269-74.

29 McDonald AD, McDonald JC, Armstrong B, et al. Occupation and pregnancy outcome. Br J Ind Med 1987:44:521-6.

30 Ahlborg G Jr, Hogstedt C, Bodin L, et al. Pregnancy outcome among working women. Scand J Work Environ Health 1989;15:227-33.

31 Hanke W, Saurel-Cubizolles MJ, Sobala W, et al. Employment status of pregnant women in central Poland and the risk of preterm delivery and smallfor-gestational-age infants. Eur J Public Health 2001;11:23-8. 